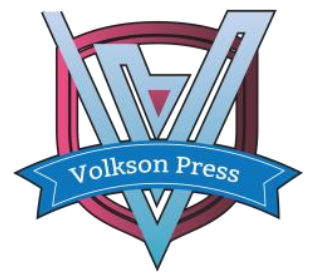

Contents List available at VOLKSON PRESS

Economics \& Management Innovations(EMI)

DOI : http://doi.org/10.26480/icemi.01.2017.359.361

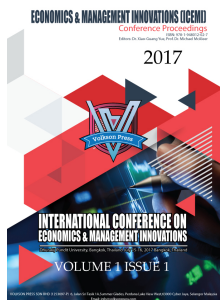

\title{
Value Stream Mapping: an analysis of the versatility of applying the method in practice
}

Dagmara Górnicka ${ }^{1}{ }^{*}$, Anna Burduk ${ }^{1}$ and Mieczysław Jagodziński ${ }^{2}$

${ }^{1}$ Faculty of Mechanical Engineering, Wroclaw University of Science and Technology, Wroclaw, Lower Silesia Province, 50-370, Poland

${ }^{2}$ Institute of Automatic Control, Silesian University of Technology, Gliwice, 44-100, Poland

*dagmara.gornicka@pwr.edu.pl

This is an open access article distributed under the Creative Commons Attribution License, which permits unrestricted use, distribution, and reproduction in any medium, provided the original work is properly cited.

\section{ARTICLE DETAILS}

\section{Article History:}

Received 02 october 2017 Accepted 06 october 2017

Available online 11 october 2017

\section{Keywords:}

Value Stream Mapping, Lean, optimization of processes, reduction of waste.

\section{ABSTRACT}

The paper analyses the practical use of Value Stream Mapping, which is a method from the Lean area. Examples of the implementation of this method in companies operating in various industries were described based on the latest publications. There were also described the ways of extending and modifying the classical method for value stream mapping.

\section{Introduction}

Value Stream Mapping is a tool used in process improvement in accordance with the Lean philosophy, with an emphasis put on the value stream analysis. This method is used in business practice, which is proved by numerous journal papers presenting practical examples of application of VSM. This paper discusses some publications from recent years to confirm whether VSM can be considered as a universal method.

\section{The essence of using Value Stream Mapping}

The first work discussed is a paper [a], in which the authors have gathered the problems and challenges that were appearing in the literature concerning the implementation of Lean tools during a period of fifteen years (1999-2014). The authors analyzed 57 papers in total. It is worth to draw attention to the ratio of theoretical works to practical works: according to the review, $79 \%$ of the analyzed literature items concerned practical aspects, while $21 \%$ - theoretical aspects. In the summary of the paper, the authors emphasize the essence of the value stream mapping method - "It is undeniable that the application of VSM provides important benefits to the productive process. That is why it is a practice applied also many companies and studied at several universities and research centers" [a]. The purpose of this paper is to investigate the versatility of the use of the value stream mapping method by analyzing the cases described in scientific journals.

\subsection{Application of VSM: medicine}

The Value Stream Mapping method has found application, inter alia, in improvement of the cytology procedure [b]. The purpose of this project was to reduce waste and errors during this procedure. There were made improvements, such as the introduction of the first in first out principle and a minimization of the batch size, which enabled "an improvement of the process resulting in higher quality, efficiency, and greater patient safety" [b]. Another example of application of Value Stream Mapping in the medical sector is the process of the procurement of endovascular stents [c]. "The current state map revealed that out of thirteen processes of the procurement of endovascular stents, only two are value-added processes. Out of the nonvalue-added processes, five processes are redundant activities that could be eliminated" [c]. The procurement of stents was based on a push system (with forecasting). The authors proposed a change to a pull system in order to improve the inventory management. They visualized it using a future state map [c]. Another example of applying the VSM method in medicine is the paper [d], written in collaboration with Novartis, in the area of development of new medicines. The authors concluded that the VSM method is more useful for the identification of operational guidelines rather than specific solutions. They substantiate it by the fact that "initial value stream mapping requires more time - counted not in hours but in days [d], as in the case of Novartis, a deeper, more specific and representative analysis involving more data is required" [d]. An additional argument is that "processes (...) are more uncertain - their results are based on observation and estimation rather than on measurement data" [d]. The Value Stream Mapping method was enriched by new solutions tailored specifically to the needs of the medical industry. In the paper [e], the authors draw attention to the progress in implementing the Lean approach in healthcare areas, and they design a new type of map for the use in the healthcare sector. The new model "includes all activities that directly affect the time of treatment" [e]. The design of the new map was tested in a Brazilian hospital, where it was compared with another value stream mapping model. The proposed solution allowed identifying bottlenecks as well as the areas, in which waste affecting the treatment of patients occurred. This model "allowed identifying the impact of waste on patients, which was not possible with the use of other mapping models" [e]. The authors emphasize that "it is important to draw attention to the fact that the identified waste and bottlenecks, which cannot be identified with the use of any mapping model other than the proposed one, may result in even 110 days of patient waiting time, which represents $56 \%$ of the total transition time" [e].

\subsection{Application of VSM: manufacturing processes}

In one of the papers [f], there was described an experiment related to Value Stream Mapping. The authors of that paper selected for the study six companies, in which problems with the door-to-door productivity occurred. In all the companies, the value stream mapping was performed, and then the effects were examined. A main goal was set for each organization. In five out of six organizations, these goals have been achieved to a lesser or greater extent - only in the case of one organization no improvement was observed [f]. Value Stream Mapping is also used as a decision support tool when introducing new solutions. An example is a company whose main problem was "how to reduce the costs when manufacturing small quantities of products in many variants" [g]. The authors proposed an improvement, which would allow eliminating the problem associated with Kanban cards being lost through real-time inventory management with the use of a system of RFID tags. After 
performing appropriate calculations and designing maps, they indicated that "the investment in the company in question gives an opportunity to create value in different areas of the production system" [g]. The Value Stream Mapping appeared to be useful also in the chemical industry. In the paper [h], the Value Stream Mapping in the area of waste logistics in a chemical plant is discussed. An important issue there is the management of production residues. The authors of the paper confirm the usability of the Value Stream Mapping method, stating that "an analysis of the organizational structure of the chemical plant together with the application of the VSM methodology for a residue management system enables a reduction in waste of raw materials" [h]. In another paper [i], there was identified a problem concerning long transition times and an unbalanced production line. The program began with the application of the Value Stream Mapping (VSM) and visualization of the process. The final results include "not only the identification of the bottleneck, but also a proposal for changes reducing the production time by $6 \%$ as well as increasing the efficiency of the process constituting the bottleneck by 32\%" [i]. The VSM method is also used in the analysis of carbon emissions in the process of manufacture of electronic products [j]. In order to propose improvements, the authors of the paper [j] identified a bottleneck in the process and an opportunity to improve the process. They noted that "the results can be achieved by improving the process constituting the bottleneck rather than by building a new manufacturing system" [j]. In addition to direct production processes, manufacturing companies also require auxiliary processes - such as product packaging. The authors emphasize the essence of packaging especially in the automotive sector, analyzing the difficulties in the implementation of standards. The paper discusses, inter alia, the role of value stream mapping in pursuit of the ideal state. The essence of one piece flow and the FIFO principle was also emphasized [k]. Another process discussed in this paper is the provision of software in the IT industry. The paper [l] analyses the implementation of an improvement in the software development process at Ericsson AB in Sweden. The solution proposed by the authors, which includes the use of the Value Stream Mapping method, was reviewed and verified by practitioners. The practitioners "responded favorably to the use of VSM and FLOW, acknowledged the realistic nature and impact on the improvement on software quality, and found the overview of the entire process using the FLOW notation very useful" [l]. In the next paper [m], there was analyzed a case study of a catalyst production process. This process was characterized by three key problems: diversity, non-linear flow and cost factors. The authors identified weaknesses of the Value Stream Mapping method associated with the problems mentioned above. Nevertheless, they define the VSM method as "a key tool for development" and propose to expand the Value Stream Mapping by the Discrete Event Simulation method. The authors notice that this solution "helps to achieve a solid, lean state and is cost-effective for the future state" [m]. Another example of expanding the Value Stream Mapping method is Sustainable Value Stream Mapping (SusVSM, SVSM). It consists in an extension of the conventional Value Stream Mapping method by a sustainable approach. This method assumes sustainable manufacturing that includes "carrying out sustainable processes and systems in order to manufacture more sustainable products" [n]. In the paper [n], a local company manufacturing TV satellite dishes was analyzed as a case study.

\subsection{Application of VSM: automotive}

The previously mentioned SVSM method is also used in the automotive industry. According to the next paper discussed [o], the Sus-VSM method was analyzed at a plant producing automotive components in India. In addition to the conventional indicators, there were selected also the following indicators: consumption of water, energy, oil, coolants and raw materials, as well as the noise levels. The proposed improvements should not only reduce the time of transition by over $50 \%$, but also reduce the water consumption by $14 \%$, the consumption of raw materials by $25 \%$, and the consumption of energy by $11 \%$. These changes "ensure a longlasting improvement in productivity (...) and support practitioners in the identification of opportunities to improve and reduce the impact of processes on the environment..." [o]. Another example of the use of the VSM method is the paper [p], in which the authors carried out value stream mapping in a factory producing parts for a manufacturer of luxury cars. The authors state that the "introduction of the Value Stream Mapping tool in the company was focused on reducing waste and increasing both the quality and efficiency of the process" [p]. In addition, "a financial analysis, essential for the decision-making process, provided better results than the decisionmaking staff expected" [p], which is also very important in the improvement process. In the next paper [q], value stream mapping was designed in a company manufacturing automotive components in São Paulo. "By analyzing the current state, it was possible to identify waste on the clutch plate assembly line" [q]. The proposal of improvements included a reduction of the transition time from over two months to 4.14 days. In addition, a reduction of the total production time by $7 \%$ and an increase in

\section{the utilization of workstations by $10 \%$ were verified [q].}

\section{Modifications of the VSM method}

In some papers discussed in this study, the Value Stream Mapping method in its original form appeared to be insufficient. For example, in one of the papers [r], the authors notice that the Value Stream Mapping method "always leads to pure pull systems and discourages the adoption of hybrid push/pull ones, although their superiority has been proven in several industrial settings". For this reason, they propose to extend the classical VSM method so that it can be applied also in MRP-based systems. This extension is referred to as synchro-MRP VSM and its usability has been examined on the example of a plant from the electronics industry. According to the authors, „the results were quite impressive" [r]. Another modification was given in the paper [s], where a manner of presenting waste with the use of Waste Identification Diagrams was described. According to the authors, "an innovative tool called Waste Identification Diagram (WID) is being developed (...) to overcome some limitations of the VSM method" [s]. The third proposal for modifying the Value Stream Mapping discussed here is accelerated VSM. The author of the next paper [t] distinguishes the manner of accelerated Value Stream Mapping. He emphasizes that this is an incorrect reasoning in the scope of continuous improvement. The subject here is "improving the questionable areas that are organized well by people who work with the process on a daily basis" [s]. The accelerated Value Stream Mapping is "based on knowledge and experience, and directly engages people where they work" [t]. The author emphasizes that there is a possibility to obtain better results by managing "chunks" of the organization in order to accelerate the improvement at continuous collaboration with the employees who delve deeper into the processes. He emphasizes that "it should be remembered that in this scenario, VSM is but a single tool in the broader improvement toolbox" [ $t]$.

\section{Conclusions}

Under this study, 20 papers from the last four years (2012-2016) and one from 2008 were analyzed. These works have been selected in a random way, but with one condition: all the journals discussed in this study are included in the ISI Master Journal List. After analyzing the papers, several conclusions can be drawn, but the most important one is that Value Stream Mapping is a method used in various sectors. It can be adapted to very different industries: medical, IT, automotive, chemical and many others. The second conclusion is that a vast majority of papers is based on case studies and thus they are based on the practical application of the method. The last but also important conclusion is that there is a clear need to develop the method and adapt it to specific needs of some companies, as in the case of the SVSM or SyVSM methods discussed here.

\section{References}

[1] A.J. Dal Forno, F.A. Pereira, F.A. Forcellini, L.M. Kipper, Value Stream Mapping: a study about the problems and challenges found in the literature from the past 15 years about application of Lean tools, „The International Journal of Advanced Manufacturing Technology", 2014, Vol. 72 , Issue 5

[2] C.W. Michael, K. Naik, M. McVicker, Value Stream Mapping of the Pap Test Processing Procedure. A Lean Approach to Improve Quality and Efficiency, "American Journal of Clinical Pathology"

[3] U.K. Teichgräber, M. de Bucourt, Applying value stream mapping techniques to eliminate non-value-added waste for the procurement of endovascular stents, "European Journal of Radiology", 2012, Vol. 81, Issue 1

[4] M. Heinzen, S. Mettler, A. Coradi, R. Boutellier, A new application of value-stream mapping in new drug development: a case study within Novartis, "Drug Discovery Today", 2015, Vol. 20, Issue 3,

[5] D.B. Henrique, A.F. Rentes, M.G. Filho \& K.F. Esposto, A new value stream mapping approach for healthcare environments, "Production Planning \& Control: The Management of Operations", 2016, Vol. 27, Issue 1

[6] I. Serrano, C. Ochoa, R. De Castro, Evaluation of value stream mapping in manufacturing system re design, "International Journal of Production Research", 2008, Vol. 46, Issue 16, ISSN: 0020-7543

[7] R. Murat Tabanli, T. Ertay, Value stream mapping and benefit-cost analysis application for value visibility of a pilot project on RFID investment integrated to a manual production control system - a case 
study, "International Journal of Advanced Manufacturing Technology", 2013, Vol. 66, Issue 5

[8] E. Michlowicz, B. Zwolińska, Mapowanie strumienia wartości w logistyce odpadów zakładu chemicznego, "Przemysł Chemiczny", 2015, Vol. 94, No. 9

[9] A. M. Atieh, H. Kaylani, A. Almuhtady, O. Al-Tamimi, A value stream mapping and simulation hybrid approach: application to glass industry, "The International Journal of Advanced Manufacturing Technology", 2016, Vol. 84, Issue 5

[10] L. Hongcheng, C. Huajun, P. Xiaoyong, A carbon emission analysis model for electronics manufacturing process based on value-stream mapping and sensitivity analysis, "International Journal Of Computer Integrated Manufacturing", 2012, Vol. 25, Issue 12

[11] A. Sunk, P. Kuhlang, W. Sihn, Improving Productivity By Deriving And Defining Target Conditions In The Value Stream Of Packing, "Transactions of FAMENA", 2014, Vol. 39, Issue 3

[12] N. Bin Ali, K. Petersen, K. Schneider, FLOW-assisted value stream mapping in the early phases of large-scale software development, "Journal of Systems and Software", 2016, Vol. 111, Issue 1

[13] D. Schmidtke, U. Heiser, O. Hinrichsen, A simulation-enhanced value stream mapping approach for optimisation of complex production environments, "International Journal of Production Research", 2014, Vol. 52 , Issue 20
[14] W. Faulkner, F. Badurdeen, Sustainable Value Stream Mapping (SusVSM): methodology to visualize and assess manufacturing sustainability performance, "Journal of Cleaner Production", 2014, Vol. 85

[15] S. Vinodh, R. Ben Ruben, P. Asokan, Life cycle assessment integrated value stream mapping framework to ensure sustainable manufacturing: a case study, "Clean Technologies and Environmental Policy", 2016, Vol. 18, Issue 1

[16] A.P. Lacerda, A.R. Xambre, H.M. Alvelos, Applying Value Stream Mapping to eliminate waste: a case study of an original equipment manufacturer for the automotive industry, International Journal of Production Research, 2016, Vol. 54, Issue 6

[17] P.F. Andrade, V.G. Pereira, E.G. Del Conte, Value stream mapping and lean simulation: a case study in automotive company, "The International Journal of Advanced Manufacturing Technology", 2015, 19 October 2015

[18] M. Bertolini, M. Braglia, G. Romagnoli, F. Zammori, Extending value stream mapping: the synchro-MRP case, "International Journal of Production Research", 2013, Vol. 51, Issue 18

[19] J. Dinis-Carvalho, F. Moreira, S. Bragança, E. Costa, A. Alves, R. Sousa, Waste identification diagrams, "Production Planning \& Control: The Management of Operations", 2015, Vol. 26, Issue 3

[20] T.T. Burton, Faster Value Stream Maps, „Industrial Engineer. Engineering and Management Solutions at Work", 2014, Vol. 46, Issue 6 